\title{
Burn and Cut Injuries Related to Job Stress among Kitchen Workers in Japan
}

\author{
Yasuo HARUYAMA ${ }^{1 *}$, Hiroe MATSUZUKI ${ }^{1,2}$, Shigeru TOMITA $^{1}$, Takashi MUTO ${ }^{1}$, \\ Takashi HARATANI ${ }^{3}$, Shigeki MUTO ${ }^{4}$ and Akiyoshi ITO $^{5}$ \\ ${ }^{1}$ Department of Public Health, Dokkyo Medical University School of Medicine, Japan \\ ${ }^{2}$ Department of Nutrition and Life Science, Kanagawa Institute of Technology, Japan \\ ${ }^{3}$ National Institute of Occupational Safety and Health, Japan \\ ${ }^{4}$ Seirei Center for Health Promotion and Preventive Medicine, Japan \\ ${ }^{5}$ University of Occupational and Environmental Health, Japan
}

Received July 24, 2013 and accepted December 17, 2013

Published online in J-STAGE January 15, 2014

\begin{abstract}
To clarify the correlation between kitchen work-related burns and cuts and job stress, a self-administered questionnaire survey was conducted involving 991 kitchen workers among 126 kitchen facilities. The demographics, condition of burns and cuts, job stress with the Brief Job Stress Questionnaire (BJSQ), health condition, and work-related and environmental factors were surveyed. Multiple logistic regression models and trend tests were used according to quartiles $(\mathrm{Q} 1$, Q2, Q3, and Q4) of each sub-scale BJSQ. After adjustment for potential confounding variables, burns/cuts were associated with a higher score category (Q4) of job demands (OR: $2.56,95 \%$ CI: 1.10-6.02/OR: 2.72, 95\% CI: 1.30-5.69), psychological stress (OR: 4.49, 95\% CI: $2.05-9.81 /$ OR: 3.52, 95\% CI: $1.84-6.72$ ), and physical stress (OR: $2.41,95 \%$ CI: $1.20-4.98 /$ OR $2.16,95 \%$ CI: 1.16-4.01). The ORs of the burn/cut injures increased from $Q 1$ to $Q 4$ with job demands ( $p$ for trend $=0.045 / 0.003)$, psychological stress $(p$ for trend $<0.001 / 0.001)$, and physical stress $(p$ for trend $=$ 0.006/0.005), respectively. These findings suggest that kitchen work-related burns and cuts are more likely to be correlated with job stress, and the higher the job stress score, the higher the frequency of burns and cuts among kitchen workers.
\end{abstract}

Key words: Burns, Cuts, Occupational injuries, Job stress, Kitchen worker

\section{Introduction}

Health and safety are priority issues in occupational health worldwide. According to the World Health Organization $^{1)}, 100$ million workers are injured and 200,000 die each year in occupational accidents. Food service industries including restaurant, hospital, and school canteen kitchens are important areas of employment in the

*To whom correspondence should be addressed.

E-mail: yasuo-h@dokkyomed.ac.jp

(C)2014 National Institute of Occupational Safety and Health world $^{2-4)}$. In Japan, there are an estimated approximately 2.6 million kitchen workers, that accounting for $4.1 \%$ of the entire employees ${ }^{5)}$.

Kitchen work has been reported to involve a marked workload, poor environment, and high risks of work-related diseases and injuries for cooks and food service work$\mathrm{ers}^{3,6,7)}$. Previous studies reported that kitchen worker had a high prevalence of musculoskeletal disorders ${ }^{8-10)}$, skin diseases $^{11,12)}$, and slipping ${ }^{13,14)}$. Furthermore, many studies reported a high risk of kitchen work-related burns or cuts among kitchen workers in many countries, such as in the $\mathrm{US}^{15-17)}$, Finland ${ }^{18)}$, Ireland ${ }^{2)}$, Canada ${ }^{3)}$, Singapore ${ }^{4)}$, 
India ${ }^{14)}$, and Japan ${ }^{19)}$. In addition, burns injury led to lost working time and public expenses ${ }^{3,13)}$.

Regarding the causes of burns, personal factors (males, younger, less job experience), work-related factors (night-shift work), and environmental factors were report$\mathrm{ed}^{15,16,19)}$. The ergonomics, equipment, and devices were considered in some previous studies ${ }^{18)}$. Riina reported that protective garments could reduce the incidence of thermal injuries ${ }^{20)}$. Risk of work-related injuries including cuts and open wounds were higher in younger males ${ }^{21)}$, and causes of cuts other than from knives were not reported ${ }^{14,18)}$.

Non-fatal occupational injuries were reportedly with a large workload, cognitive demands, a marked stress reaction, and low level of job control ${ }^{2-25)}$, but these studies did not refer to burns or cuts during kitchen work. With regard to the association between kitchen work and job stress, the prevalence of low back pain and epicondylitis was investigated ${ }^{26,27)}$. However, no study discussed the association between kitchen work-related burns and cuts and job stress in kitchen workers. Our hypothesis in this study was that more burns and cuts occur in kitchen workers with a higher job stress.

The purpose of this study was to clarify the correlations between the work-related burns and cuts and job demands, and physical and psychological stress among kitchen workers.

\section{Methods}

\section{Subjects and study design}

The subjects in this study were 991 workers aged from 17 to $68 \mathrm{yr}$ old in 126 kitchen facilities, which included 103 primary schools (578 workers, $58.3 \%$ ), 17 hospitals (343 workers, $34.6 \%$ ), and 6 restaurants (70 workers, $7.1 \%$ ) in central Japan. The 126 kitchen facilities were recruited from a list that they were compiled by occupational doctors and researchers of this study, as previously reported $^{19,30)}$. All the schools were public schools, and 81 of them were located in the Chubu region, while 22 were located in the Tokyo metropolitan area. The number of kitchen workers varied from 2 to 20 in each school. The principal task of these workers was to provide lunches for all pupils $5 \mathrm{~d}$ a week. The 11 hospitals were regional hub, university and affiliated hospitals. The six nursing homes were related institutes. Nine out of the 11 hospitals were located in the Tokyo metropolitan area, and the others were in Shikoku and Tohoku regions. The number of workers varied from 10 to 60 in each hospital. Five nursing homes were located in the Chubu region, and the remaining one was in the Tokyo metropolitan area. Five to nine workers worked in each nursing home. Kitchen workers in these institutions provided breakfast, lunch, and dinner for all residents. The six restaurants were located in the Tokyo metropolitan area. The number of workers in the restaurants varied from 7 to 20 . All restaurants were open until midnight and two of them were open $24 \mathrm{~h}$. Kitchen workers in these restaurants provided meals at irregular times. A cross-sectional study was conducted involving a self-administered, anonymous questionnaire distributed to all employees during August to November 2006.

The protocol of this study was approved by the Ethics Committee of Dokkyo Medical University. All subjects were fully informed of the purpose of the study, and then gave written informed consent.

\section{Personal questionnaire}

1. Demographic and work-related items: The items in the personal questionnaire survey included the age, gender, height, weight, years working in a kitchen, working hours per day, working system, shift, and types of main job. Personal health conditions were assessed with the question: "do you have finger deformation, pain of the lower back, arthralgia, or hand dermatitis requiring medication?" The body mass index (BMI) was calculated as the body weight $(\mathrm{kg})$ divided by the square of the height $\left(\mathrm{m}^{2}\right)$. There were 809 responders, and the response rate was $81.6 \%$. Of the 809 responders, those with missing values on the gender, age, burns, cuts, and job stress were excluded, and 740 (570 females and 170 males) kitchen workers were identified as the subjects, with an effective response rate of $74.7 \%$.

2. Burns and cuts assessment: The information on burns and cuts was collected from self-reported questionnaire of subjects. The two questions and possible response categories were as follows: 1) have you experienced any burns during kitchen work in the last year? $(\leq 5$ times/ $>5$, $\leq 10$ times $/>10, \leq 20$ times/ $>20$ times). 2 ) Have you experienced any cuts during kitchen work in the last year? $(\leq 5$ times $/>5, \leq 10$ times $/>10, \leq 20$ times $/>20$ times). For the burns $(+)$ and cuts $(+)$ those who were injured six times or more in the last year were the frequent group, and they were used to analyze the correlation between each factor and injuries according to Tomita's study ${ }^{19)}$.

3. Job stress assessment: The Brief Job Stress Questionnaire (BJSQ), a 57-item multidimensional job stress questionnaire, was used to measure job demand (7 items), job control (3 items), human relationship ( 3 items), fitness of work ( 3 items), working environment (1 item), physical (11 items), psychological (18 items) stress, social support 
Table 1. Characteristics of demographics, health condition, and work-related and environmental factors in kitchen workers

\begin{tabular}{|c|c|c|c|c|c|c|c|}
\hline & \multirow{2}{*}{$\frac{\mathrm{All}^{\mathrm{a}}}{\mathrm{n}(\%)}$} & \multirow{2}{*}{$\frac{\text { Burns }(+)^{\mathrm{b}}}{\mathrm{n}(\%)}$} & \multirow{2}{*}{$\begin{array}{c}\text { Burns }(-)^{\mathrm{b}} \\
\mathrm{n}(\%)\end{array}$} & \multirow{2}{*}{$p$-value } & \multirow{2}{*}{$\frac{\text { Cuts }(+)^{\mathrm{b}}}{\mathrm{n}(\%)}$} & \multirow{2}{*}{$\begin{array}{c}\text { Cuts }(-)^{\mathrm{b}} \\
\mathrm{n}(\%)\end{array}$} & \multirow{2}{*}{$p$-value } \\
\hline & & & & & & & \\
\hline \multicolumn{8}{|l|}{ Personal factors } \\
\hline \multicolumn{8}{|l|}{ Gender } \\
\hline Males & $170(23.0)$ & $37(21.8)$ & $133(78.2)$ & 0.015 & $32(18.8)$ & $138(81.2)$ & 0.083 \\
\hline Females & $570(77.0)$ & $80(14.0)$ & $490(86.0)$ & & $144(25.3)$ & $426(74.7)$ & \\
\hline \multicolumn{8}{|l|}{ Age, yr } \\
\hline$\leq 35$ & $223(30.1)$ & $43(19.3)$ & $180(80.7)$ & 0.205 & $61(27.4)$ & $162(72.6)$ & 0.313 \\
\hline $35-55$ & $414(55.9)$ & $61(14.7)$ & $353(85.3)$ & & $91(22.0)$ & $323(78.0)$ & \\
\hline $55 \leq$ & $103(13.9)$ & $13(12.6)$ & $90(87.4)$ & & $24(23.3)$ & $79(76.7)$ & \\
\hline \multicolumn{8}{|l|}{ Health condition } \\
\hline \multicolumn{8}{|l|}{ BMI, $\mathrm{kg} / \mathrm{m}^{2}$} \\
\hline$<25.0$ & $590(84.5)$ & $94(15.8)$ & $502(84.2)$ & 0.364 & $141(23.7)$ & $455(76.3)$ & 0.532 \\
\hline$\geq 25.0$ & $109(15.5)$ & $21(19.3)$ & $88(80.7)$ & & $28(25.7)$ & $81(74.3)$ & \\
\hline \multicolumn{8}{|c|}{ Finger deformation } \\
\hline Yes & $10(1.4)$ & $2(20.0)$ & $8(80.0)$ & 0.715 & $4(40.0)$ & $6(60.0)$ & 0.225 \\
\hline No & $730(98.6)$ & $115(15.8)$ & $615(84.2)$ & & $172(23.6)$ & $558(76.4)$ & \\
\hline Pain of the loy & & & & & & & \\
\hline Yes & $123(16.6)$ & $24(19.5)$ & $99(80.5)$ & 0.218 & $38(30.9)$ & $85(69.1)$ & 0.043 \\
\hline No & $617(83.4)$ & $93(15.1)$ & $524(84.9)$ & & $138(22.4)$ & $479(77.6)$ & \\
\hline Other arthralg & & & & & & & \\
\hline Yes & $91(12.3)$ & $21(23.1)$ & $70(76.9)$ & 0.042 & $31(34.1)$ & $60(65.9)$ & 0.014 \\
\hline No & $649(87.7)$ & $96(14.8)$ & $553(85.2)$ & & $145(22.3)$ & $504(77.7)$ & \\
\hline Dermatitis (ha & & & & & & & \\
\hline Yes & $43(5.8)$ & $11(25.6)$ & $32(74.4)$ & 0.070 & $15(34.9)$ & $28(65.1)$ & 0.078 \\
\hline No & $697(94.2)$ & $106(15.2)$ & $591(84.8)$ & & $161(23.1)$ & $536(76.1)$ & \\
\hline Work-related fac & & & & & & & \\
\hline Working in a 1 & & & & & & & \\
\hline$\leq 2$ & $274(44.6)$ & $53(19.3)$ & $221(80.7)$ & 0.115 & $68(24.8)$ & $206(75.2)$ & 0.282 \\
\hline 2 to 5 & $169(27.5)$ & $20(11.8)$ & $149(88.2)$ & & $31(18.3)$ & $138(81.7)$ & \\
\hline $6 \leq$ & 171 (27.9) & $30(17.5)$ & $141(82.5)$ & & $38(22.2)$ & $133(77.8)$ & \\
\hline Job hours, hr/ & & & & & & & \\
\hline$<8$ & $217(30.0)$ & $32(14.7)$ & $185(85.3)$ & 0.097 & $50(23.0)$ & $167(76.2)$ & 0.955 \\
\hline 8 & $423(58.4)$ & $62(14.7)$ & $361(85.3)$ & & $102(24.1)$ & $321(75.9)$ & \\
\hline$>8$ & $84(11.6)$ & $20(23.8)$ & $64(76.2)$ & & $20(23.8)$ & $64(76.2)$ & \\
\hline Working syste & & & & & & & \\
\hline Part-time & $466(64.4)$ & $81(17.4)$ & $385(82.6)$ & 0.180 & $114(24.5)$ & $352(75.5)$ & 0.630 \\
\hline Regular & $258(35.6)$ & $35(13.6)$ & $223(86.4)$ & & $59(22.9)$ & $199(77.1)$ & \\
\hline Shift & & & & & & & \\
\hline Day service & $536(74.8)$ & $87(16.2)$ & $449(83.3)$ & 0.542 & $130(24.3)$ & $406(75.7)$ & 0.796 \\
\hline Day shift & $165(23.0)$ & $25(15.2)$ & $140(84.8)$ & & $37(22.4)$ & $128(77.6)$ & \\
\hline Other & $16(2.2)$ & $1(6.3)$ & $15(93.8)$ & & $3(18.8)$ & $13(81.3)$ & \\
\hline Type of main & & & & & & & \\
\hline Cooking & $343(46.4)$ & $38(11.1)$ & 305 (88.9) & 0.001 & $75(21.9)$ & $268(78.1)$ & 0.521 \\
\hline Washing up & $56(7.6)$ & $7(12.5)$ & $49(87.5)$ & & $14(25.0)$ & $42(75.0)$ & \\
\hline Other & $341(46.1)$ & $72(21.1)$ & $269(78.9)$ & & $87(25.5)$ & $254(74.5)$ & \\
\hline Output, meals & & & & & & & \\
\hline$<750$ & $391(52.8)$ & $69(17.6)$ & $322(82.4)$ & 0.147 & $87(22.3)$ & $304(77.7)$ & 0.300 \\
\hline $750 \leq$ & $349(47.2)$ & $48(13.8)$ & $301(86.2)$ & & $89(25.5)$ & $260(74.5)$ & \\
\hline Environmental fa & & & & & & & \\
\hline Size of kitche & & & & & & & \\
\hline $200 \leq$ & $408(55.1)$ & $54(13.2)$ & $354(86.8)$ & 0.033 & $99(24.3)$ & $309(75.5)$ & 0.733 \\
\hline$<200$ & 332 ( 44.9) & $63(19.0)$ & $269(81.0)$ & & $77(23.2)$ & $255(76.8)$ & \\
\hline Type of floor & & & & & & & \\
\hline Dry & $427(60.3)$ & $59(13.8)$ & $368(86.2)$ & 0.248 & $97(22.7)$ & $330(77.3)$ & 0.593 \\
\hline Semi-wet & $109(15.4)$ & $18(16.5)$ & $91(83.5)$ & & $29(26.6)$ & $80(73.4)$ & \\
\hline Wet & $172(24.3)$ & $33(19.2)$ & $139(80.8)$ & & $44(25.6)$ & $128(74.4)$ & \\
\hline Type of heat & & & & & & & \\
\hline Electric & $378(51.1)$ & $49(13.0)$ & $329(87.0)$ & 0.030 & $89(23.5)$ & $289(76.5)$ & 0.876 \\
\hline Gas & $362(48.9)$ & $68(18.8)$ & $294(81.2)$ & & $87(24.0)$ & $275(76.0)$ & \\
\hline Type of kitche & & & & & & & \\
\hline School & $393(53.1)$ & $57(14.5)$ & $336(85.5)$ & $<0.001$ & $108(27.5)$ & $285(72.5)$ & 0.023 \\
\hline Hospital & $292(39.1)$ & $37(12.7)$ & $255(87.3)$ & & $54(18.5)$ & $238(81.5)$ & \\
\hline Restaurant & $55(7.4)$ & $23(41.8)$ & $32(58.2)$ & & $14(25.5)$ & $41(74.5)$ & \\
\hline
\end{tabular}

a: Missing values were excluded.

b: Burns and cuts $(+)$ more than 5 times and $(-)$ less than 5 times in the last year by self-report.

c: $p$-value from $\chi^{2}$ test. 
Table 2. Association between burn injuries and job stress using multiple logistic regression models

\begin{tabular}{|c|c|c|c|c|c|c|c|c|c|c|c|c|c|c|}
\hline \multirow{2}{*}{$\begin{array}{c}\text { Sub scales of } \\
\text { BJSQ }\end{array}$} & \multirow{2}{*}{$\mathrm{n}$} & \multirow{2}{*}{$\begin{array}{l}\text { No of burns } \\
(>5 \text { times/year) }\end{array}$} & \multirow{2}{*}{$\%$} & \multicolumn{2}{|c|}{ Model 1} & \multicolumn{2}{|c|}{ Model 2} & \multicolumn{2}{|c|}{ Model 3} & \multicolumn{2}{|c|}{ Model 4} & \multicolumn{2}{|c|}{ Model 5} & \multirow{2}{*}{$\begin{array}{l}p \text { for } \\
\text { trend }\end{array}$} \\
\hline & & & & OR & $95 \% \mathrm{CI}$ & OR & $95 \% \mathrm{CI}$ & OR & $95 \% \mathrm{CI}$ & OR & $95 \% \mathrm{CI}$ & OR & $95 \% \mathrm{CI}$ & \\
\hline \multicolumn{15}{|c|}{ Job demands, point } \\
\hline Q1 $(<23)$ & 143 & 17 & 11.9 & 1.00 & & 1.00 & & 1.00 & & 1.00 & & 1.00 & & \multirow{4}{*}{0.045} \\
\hline Q2 $(\geq 23,<26)$ & 222 & 33 & 14.9 & 1.33 & $0.71-2.50$ & 1.31 & $0.68-2.52$ & 1.52 & $0.73-3.15$ & 1.62 & $0.82-3.19$ & 1.63 & $0.73-3.65$ & \\
\hline Q3 $(\geq 26,<30)$ & 226 & 33 & 14.6 & 1.37 & $0.73-2.58$ & 1.32 & $0.68-2.56$ & 1.38 & $0.66-2.91$ & 1.61 & $0.81-3.18$ & 1.50 & $0.66-3.42$ & \\
\hline Q4 ( $\geq 30)$ & 149 & 34 & 22.8 & 2.43 & $1.27-4.63$ & 2.34 & $1.19-4.59$ & 2.46 & $1.15-5.26$ & 2.84 & $1.40-5.76$ & 2.56 & $1.10-6.02$ & \\
\hline \multicolumn{15}{|c|}{ Psychological stress, point } \\
\hline Q1 $(<11)$ & 162 & 15 & 9.3 & 1.00 & & 1.00 & & 1.00 & & 1.00 & & 1.00 & & \multirow{4}{*}{$<0.001$} \\
\hline Q2 $(\geq 11,<18)$ & 194 & 23 & 11.9 & 1.29 & $0.65-2.57$ & 1.21 & $0.61-2.43$ & 1.17 & $0.56-2.48$ & 1.77 & $0.83-3.80$ & 1.60 & $0.69-3.69$ & \\
\hline Q3 $(\geq 18,<25)$ & 176 & 27 & 15.3 & 1.75 & $0.89-3.43$ & 1.59 & $0.80-3.16$ & 1.54 & $0.75-3.19$ & 2.62 & $1.23-5.57$ & 2.39 & $1.03-5.54$ & \\
\hline Q4 ( $\geq 25)$ & 206 & 52 & 25.2 & 3.27 & $1.76-6.09$ & 2.93 & $1.56-5.52$ & 3.24 & $1.66-6.32$ & 4.72 & $2.33-9.57$ & 4.49 & $2.05-9.81$ & \\
\hline \multicolumn{15}{|c|}{ Physical stress, point } \\
\hline Q1 $(<4)$ & 175 & 23 & 13.1 & 1.00 & & 1.00 & & 1.00 & & 1.00 & & 1.00 & & \multirow{4}{*}{0.006} \\
\hline Q2 $(\geq 4,<7)$ & 170 & 21 & 12.4 & 1.00 & $0.53-1.89$ & 0.87 & $0.51-1.85$ & 0.85 & $0.42-1.72$ & 1.02 & $0.51-2.06$ & 0.85 & $0.39-1.86$ & \\
\hline Q3 $(\geq 7,<11)$ & 191 & 26 & 13.6 & 1.13 & $0.61-2.09$ & 0.96 & $0.51-1.81$ & 1.05 & $0.54-2.03$ & 1.23 & $0.64-2.39$ & 1.02 & $0.49-2.14$ & \\
\hline Q4 ( $\geq 11)$ & 203 & 47 & 23.2 & 2.30 & $1.31-4.04$ & 2.03 & $1.12-3.66$ & 1.98 & $1.06-3.71$ & 2.82 & $1.53-5.21$ & 2.44 & $1.20-4.98$ & \\
\hline
\end{tabular}

Model 1 adjusted for sex and age. Model 2 adjusted for sex, age, and health factors included in bmi, finger deformation, dermatitis, pain of the lower back, and other arthralgia. Model 3 adjusted for sex, age, and work-related factors included in experience on kitchen work, working system, job hour, shift, type of main job, and output. Model 4 adjusted for sex, age, and environmental factors included in size of kitchen, type of floor condition, type of heat and type of kitchen. Model 5 adjusted for sex, age, all health, work-related, and environmental factors.

(9 items), and job and family satisfaction $(2 \text { items })^{28)}$. The score was calculated for each item, and the categories were based on a 4-point Likert scale ranging from "strongly disagree" $=1$ to "strongly agree" $=4$. A higher score means a higher stressor and stress. In this study, the sub-scales of job demand, physical stress, and psychological stress were assessed. All of these scales have been proven to be acceptable with high levels of internal consistency, reliability, and factor-based validity with high Cronbach's alpha coefficients (i.e., job demand: 0.70 ; job control: 0.62; psychological stress: 0.88 ; physical stress: 0.73$)^{29)}$. In this study sample, Cronbach's alpha coefficients of 7-item job demands, 11-item physical stress, and 18-item psychological stress were $0.73,0.85$, and 0.92 , respectively. To clarify whether the degree of job stress was correlated with injures, the participants were divided into quartiles (Q1, Q2, Q3, and Q4) according to the 25, 50, and 75 percentiles of job demands and physical and psychological stress scores of this study sample.

\section{Environmental questionnaire}

The survey on kitchen facilities included: the output of meals per day, size and type of kitchen, type of floor state (dry, semi-wet, or wet), type of main heat (electric or gas), and type of kitchen (school, hospital-affiliated nursing homes, and restaurant ${ }^{19,30)}$. All administrators of the 126 kitchens answered the questionnaire on kitchen facilities.

\section{Statistical analysis}

The variables of the survey were re-categorized according to our previous studies ${ }^{19,30)}$ as follows: age $(<35 / 35 \sim 55 / 55 \leq \mathrm{yr})$, BMI $\left(<25 / 25 \leq \mathrm{kg} / \mathrm{m}^{2}\right)$, years of employment $(<3 / 3 \leq \mathrm{yr})$, working hours $(<8 / 8 / 8 \leq \mathrm{hr})$, working system (regular/part-time), shift (day shift/split shift/ other), type of main job (cooking/washing up/other), production level $(<750 / 750 \leq$ meals per day), size of kitchen $\left(<200 / 200 \leq \mathrm{m}^{2}\right)$, and type of floor state (wet/semi-dry/dry).

The Chi-square test was for category variables. Multiple logistic regression models (independent variable $=$ burn or cut, dependent variables=job stress (job demands or physical or psychological stress response), and confounding factors were used. To discuss the correlation between burns or cuts and job stress, Model 1 was adjusted for gender and age, Model 2 involved personal health factors, Model 3 involved work-related factors, Model 4 involved kitchen-based environmental factors, and Model 5 was adjusted for all factors.

Probability values $<0.05$ were considered significant. The IBM SPSS 19 for Windows (IBM SPSS Inc., Tokyo, Japan) was used for all statistical analyses. 
Table 3. Association between cut injuries and job stress using multiple logistic regression models

\begin{tabular}{|c|c|c|c|c|c|c|c|c|c|c|c|c|c|c|}
\hline \multirow{2}{*}{$\begin{array}{c}\text { Sub scales of } \\
\text { BJSQ }\end{array}$} & \multirow{2}{*}{$\mathrm{n}$} & \multirow{2}{*}{$\begin{array}{c}\text { No of cuts } \\
(>5 \text { times/year) }\end{array}$} & \multirow{2}{*}{$\%$} & \multicolumn{2}{|c|}{ Model 1} & \multicolumn{2}{|c|}{ Model 2} & \multicolumn{2}{|c|}{ Model 3} & \multicolumn{2}{|c|}{ Model 4} & \multicolumn{2}{|c|}{ Model 5} & \multirow{2}{*}{$\begin{array}{l}p \text { for } \\
\text { trend }\end{array}$} \\
\hline & & & & OR & $95 \% \mathrm{CI}$ & OR & $95 \% \mathrm{CI}$ & OR & $95 \% \mathrm{CI}$ & OR & $95 \% \mathrm{CI}$ & OR & $95 \% \mathrm{CI}$ & \\
\hline \multicolumn{15}{|c|}{ Job demands, point } \\
\hline Q1 $(<23)$ & 181 & 25 & 17.5 & 1.00 & & 1.00 & & 1.00 & & 1.00 & & 1.00 & & \multirow{4}{*}{0.003} \\
\hline Q2 $(\geq 23,<26)$ & 207 & 42 & 18.9 & 1.10 & $0.64-1.90$ & 1.40 & $0.72-2.74$ & 1.31 & $0.69-2.50$ & 1.16 & $0.66-2.04$ & 1.28 & $0.64-2.59$ & \\
\hline Q3 $(\geq 26,<30)$ & 183 & 55 & 24.3 & 1.46 & $0.86-2.48$ & 1.60 & $0.83-3.10$ & 1.52 & $0.81-2.88$ & 1.52 & $0.88-2.62$ & 1.63 & $0.82-3.27$ & \\
\hline Q4 ( $\geq 30)$ & 169 & 54 & 36.2 & 2.72 & $1.57-4.72$ & 2.91 & $1.50-5.83$ & 2.92 & $1.51-5.67$ & 2.79 & $1.57-4.96$ & 2.72 & $1.30-5.69$ & \\
\hline \multicolumn{15}{|c|}{ Psychological stress, point } \\
\hline $\mathrm{Q} 1(<11)$ & 162 & 26 & 16.0 & 1.00 & & 1.00 & & 1.00 & & 1.00 & & 1.00 & & \multirow{4}{*}{$<0.001$} \\
\hline Q2 $(\geq 11,<18)$ & 194 & 42 & 21.6 & 1.43 & $0.83-2.46$ & 1.57 & $0.82-3.02$ & 1.41 & $0.76-2.63$ & 1.62 & $0.82-2.84$ & 1.56 & $0.80-3.05$ & \\
\hline Q3 $(\geq 18,<25)$ & 176 & 41 & 23.3 & 1.57 & $0.91-2.72$ & 1.85 & $0.96-3.58$ & 1.57 & $0.84-2.63$ & 1.85 & $1.04-3.29$ & 1.73 & $0.86-3.46$ & \\
\hline Q4 ( $\geq 25)$ & 206 & 66 & 32.0 & 2.42 & $1.45-4.04$ & 3.53 & $1.90-6.68$ & 3.08 & $1.72-5.52$ & 2.82 & $1.64-4.85$ & 3.52 & $1.84-6.72$ & \\
\hline \multicolumn{15}{|c|}{ Physical stress, point } \\
\hline Q1 $(<4)$ & 175 & 32 & 18.3 & 1.00 & & 1.00 & & 1.00 & & 1.00 & & 1.00 & & \multirow{4}{*}{0.005} \\
\hline Q2 $(\geq 4,<7)$ & 170 & 29 & 17.1 & 0.89 & $0.51-1.56$ & 0.82 & $0.42-1.58$ & 0.82 & $0.43-1.53$ & 0.90 & $0.50-1.60$ & 0.79 & $0.40-1.57$ & \\
\hline Q3 $(\geq 7,<11)$ & 191 & 47 & 24.6 & 1.38 & $0.83-2.30$ & 1.37 & $0.76-2.47$ & 1.33 & $0.75-2.34$ & 1.41 & $0.83-2.38$ & 1.17 & $0.63-2.16$ & \\
\hline $\mathrm{Q} 4(\geq 11)$ & 203 & 67 & 33.0 & 2.15 & $1.30-3.45$ & 2.31 & $1.29-4.12$ & 2.13 & $1.23-3.70$ & 2.32 & $1.39-3.86$ & 2.16 & $1.16-4.01$ & \\
\hline
\end{tabular}

Model 1 adjusted for sex and age. Model 2 adjusted for sex, age, and health factors included in bmi, finger deformation, dermatitis, pain of the lower back, and other arthralgia. Model 3 adjusted for sex, age, and work-related factors included in experience on kitchen work, working system, job hour, shift, type of main job, and output. Model 4 adjusted for sex, age, and environmental factors included in size of kitchen, type of floor condition, type of heat and type of kitchen. Model 5 adjusted for sex, age, all health, work-related, and environmental factors.

\section{Results}

In the total of 740 kitchen workers, the frequencies of four categories were $84.2,12.4,2.6$, and $0.8 \%$ for burns, and $76.2,17.2,4.6$, and $2.0 \%$ for cuts, respectively. Together with 2-4 categories, 117 (15.8\%) kitchen workers had experienced burns (more than 5 times) and 176 (23.8\%) had experienced cuts (more than 5 times) in the last year.

Table 1 presents the demographic characteristics, personal health conditions, and work-related and environmental factors between those with higher and lower burn and cut rates in kitchen workers. Kitchen workers who had higher burn rates showed correlations with gender, hand dermatitis, arthralgia which excluded lower back pain, size of kitchen, type of heat, working hours, type of main job, and type of kitchen. Kitchen workers who had higher cut rates showed some differences $(p<0.1)$ between genders, hand dermatitis, arthralgia which excluded lower back pain, and pain of the lower back, and type of kitchen.

The workers who had burns (+) from Q1 (lower score) to Q4 (higher score) comprised 11.9, 14.9, 14.6, and $22.8 \%$ for the job demand, $9.3,11.9,15.3$, and $25.2 \%$ for the psychological stress response, and 13.1, 12.4, 13.6, and $23.2 \%$ for the physical stress response in Table 2. Compared with Q1 of each sub-scale of BJSQ, Q4 in Model 1 showed higher Odds ratios with the $95 \%$ confidence interval (CI) of burn injuries (+). Based on Models 2, 3, and 4, the ORs remain higher adjusted for the health condition, and work-related and environmental factors, respectively. Model 5 shows the burns (+) associated with job demands (OR: 2.56, 95\% CI: 1.10-6.02), psychological stress (OR: 4.49, 95\% CI: 2.05-9.81), and physical stress (OR: 2.44, 95\% CI: 1.20-4.98) after adjustment for sex, age, health conditions, work-related factors, and environmental factors. The ORs for higher burn rates increased from Q1 to Q4 with job demands ( $p$ for trend $=0.045$ ), psychological stress ( $p$ for trend $<0.001$ ), and physical stress ( $p$ for trend $=0.006$ ).

Table 3 shows that workers who had cuts from Q1 to Q4 comprised 17.5, 18.9, 24.3, and 36.2\% for job demand, $16.0,21.6,23.3$, and $32.0 \%$ for psychological stress, and 18.3, 17.1, 24.6, and 33.0\% for physical stress. Compared with Q1 of each sub-scale of BJSQ, Q4 in Model 1 showed higher ORs with $95 \%$ CI of cuts. After adjustmentfor personal health conditions or environmental factors, Models 2, 3, and 4 continued to show an association between job stress and higher cut rates. In the final Model 5 , a higher cut rate was associated with the job demand (OR: 2.72, 95\% CI: 1.30-5.69), psychological stress (OR: 3.52, 95\% CI: 1.84-6.72), and physical stress (OR: 2.16, 95\% CI: 1.16-4.01) after adjustment for sex, age, health 
conditions, and environmental factors. The ORs of higher burn rates increased from Q1 to Q4 with job stress ( $p$ for trend $<0.003$ ), psychological stress ( $p$ for trend $<0.001$ ), and physical stress $(p$ for trend $=0.005$ ).

\section{Discussion}

The results of this study suggest that workers with marked job demands and psychological and physical stress show significantly higher frequencies of burns and cuts. To the best of our knowledge, this is the first study to show that job stress included in job demands and psychological and physical stress is an important independent factor related to burns and cuts occurring in kitchen workers after adjustment for confounding factors (age, sex, health condition, and work-related and environmental factors).

Although no previous study has directly discussed the association between job stress and burns and cuts in kitchen workers, some studies showed that job stress was related to work-related injuries in the manufacturing industry ${ }^{22,23)}$. Kim et al reported that a high job demand (OR 1.71, 95\% CI 1.13-2.59) and high job strain (OR 3.57, 95\% CI 1.62-7.86) were associated with and an increased risk of occupational injury including cuts ${ }^{24)}$. So, these results of previous studies are considered to indirectly support our findings.

Furthermore, it was appropriate to evaluate the job stress of kitchen workers using BJSQ in this study. Previous studies showed that job stress negatively affected job performance ${ }^{31,32)}$ and cognitive performance such as

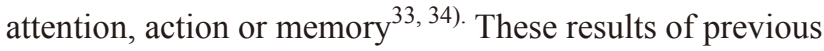
studies support our findings from our multiple logistic regression analysis that the risk of occupational burns and/or cut injuries increased with the score of each sub-scale of the BJSQ from Q1 (the lowest quartile) to Q4 (the higher quartile), and that especially, the frequency of the burn and cut injuries significantly correlated with the Q4 quartile.

\section{Strengths and limitations}

There are several strengths regarding the present study. 1) All workers of the 126 kitchens were surveyed, with a high response rate and appropriate sample size. 2) Other potential confounding variables concerning the personal health conditions, work-related factors, and working environmental factors were surveyed. 3) The multiple logistic regression models were performed to remove other potential confounding effects of personal health conditions and work-related and environmental factors.

On the other hand, there are several limitations that should be mentioned. First, because it was a crosssectional study, a causal relationship between burns or cuts and job stress could not be interpreted. Hereafter, a cohort study should be carried out to investigate the casual relationship between job stress and injuries. Second, the frequency of burns and cuts was evaluated with a selfreported questionnaire, and the severity of burns/cuts was not analyzed. Although the kitchen workers were asked whether they had experienced burns and cuts during the last year, there was some recall bias in the respondents of this study. It is important to use medical care and insurance records, but that unrecorded occupational injuries could not be take account of. Based on Heinrich's law, minor injuries such as unrecorded burns could be included in the self-reported questionnaire and then the results of this study would be more likely to reflect the real condition of workers' injuries and would be more helpful to reduce serious burns and cuts in the work setting. Third, the workers were nested in different kitchens located within different industries, but the analysis did not take this into consideration. Fourth, the one hundred and twenty-six kitchens were non-randomly selected, so a selection bias could not be avoided; therefor, the results of this study should be carefully generalized.

This study showed that health and safety measures must consider job stress as an important factor in food service industries.

\section{Conclusions}

Kitchen work-related burns and cuts are more likely to be correlated with job stress. A higher job stress score is correlated with a higher frequency of burns and cuts. This suggests that job stress is an independent risk factor, and the establishment of injury prevention programs for burns and cuts could focus on the reduction of job stress correlated with job demand and psychological and physical stress in kitchen work.

\section{References}

1) World Health Organization Office of occupational health. Declaration on occupational health for all. Beijing, China: World Health Organization; 11-4 October 1994. http:// www.who.int/occupational_health/en/oehdeclaration94e.pd f\#search='Declaration+on+occupational+health+for+all.+ Bejing\%2C'. Accessed March 1, 2013.

2) Gleeson $D$ (2001) Health and safety in the catering industry. Occup Med (Lond) 51, 385-91. [Medline] [CrossRef]

3) Alamgir H, Swinkels H, Yu S, Yassi A (2007) Occupational 
injury among cooks and food service workers in the healthcare sector. Am J Ind Med 50, 528-35. [Medline] [CrossRef]

4) Teo S, Teik-Jin Goon A, Siang LH, Lin GS, Koh D (2009) Occupational dermatoses in restaurant, catering and fastfood outlets in Singapore. Occup Med (Lond) 59, 466-71. [Medline] [CrossRef]

5) The Japan institute for labour police and tranining. Statistics information. http://www.jil.go.jp/kokunai/statistics/ sansyoku/sansyoku.html. Accessed March 1, 2013.

6) Buchanan S, Vossenas P, Krause N, Moriarty J, Frumin E, Shimek JA, Mirer F, Orris P, Punnett L (2010) Occupational injury disparities in the US hotel industry. Am J Ind Med 53, 116-25. [Medline] [CrossRef]

7) Filippelli C, Verso MG, Amicarelli V, Di Famiani M, Tomei G, Pimpinella B, Casale T, Capozzella A, Ciarrocca M, Rosati MV, Tomei F (2008) [Food service workers and cooks: occupational risk assessment]. Ann Ig 20, 57-67 (in Italian with English abstract). [Medline]

8) Nakamura R, Ono Y, Horii E, Tsunoda K, Takeuchi Y (1993) The aetiological significance of work-load in the development of osteoarthritis of the distal interphalangeal joint. J Hand Surg 18, 540-2. [Medline] [CrossRef]

9) Pehkonen I, Miranda H, Haukka E, Luukkonen R, Takala EP, Ketola R, Leino-Arjas P, Riihimäki H, Viikari-Juntura E (2009) Prospective study on shoulder symptoms among kitchen workers in relation to self-perceived and observed work load. Occup Environ Med 66, 416-23. [Medline] [CrossRef]

10) Haukka E, Leino-Arjas $P$, Solovieva $S$, Ranta R, ViikariJuntura E, Riihimäki H (2006) Co-occurrence of musculoskeletal pain among female kitchen workers. Int Arch Occup Environ Health 80, 141-8. [Medline] [CrossRef]

11) Gawkrodger DJ, Lloyd MH, Hunter JA (1986) Occupational skin disease in hospital cleaning and kitchen workers. Contact Dermat 15, 132-5. [Medline] [CrossRef]

12) Kanerva L, Estlander T, Jolanki R (1996) Occupational allergic contact dermatitis from spices. Contact Dermat 35, 157-62. [Medline] [CrossRef]

13) Verma SK, Chang WR, Courtney TK, Lombardi DA, Huang YH, Brennan MJ, Mittleman MA, Perry MJ (2010) Workers' experience of slipping in U.S. limited-service restaurants. J Occup Environ Hyg 7, 491-500. [Medline] [CrossRef]

14) Kokane S, Tiwari RR (2011) Occupational health problems of highway restaurant workers of Pune, India. Toxicol Ind Health 27, 945-8. [Medline] [CrossRef]

15) Horwitz IB, McCall BP (2004) Quantification and risk analysis of occupational burns: Oregon workers' compensation claims, 1990 to 1997. J Burn Care Rehabil 25, 328-36. [Medline] [CrossRef]

16) Horwitz IB, McCall BP (2005) An analysis of occupational burn injuries in Rhode Island: workers' compensation claims, 1998 to 2002. J Burn Care Rehabil 26, 505-14.
[Medline] [CrossRef]

17) Suzman MS, Sobocinski K, Himel H, Yurt RW (2001) Major burn injuries among restaurant workers in New York City: an underappreciated public health hazard. J Burn Care Rehabil 22, 429-34. [Medline] [CrossRef]

18) Pekkarinen A, Anttonen H, Niskanen J (1996) Assessment of Health Risks in Canteen Kitchens. Int J Occup Saf Ergon 2, 262-7. [Medline]

19) Tomita $S$, Muto $T$, Matsuzuki $H$, Haruyama $Y$, Ito A, Muto S, Haratani T, Seo A, Ayabe M, Katamoto S (2013) Risk factors for frequent work-related burn and cut injuries and low back pain among commercial kitchen workers in Japan. Ind Health 51, 297-306. [Medline] [CrossRef]

20) Riina LH, Simpson RL, Gudjonsson O, Glickman LT, Harris SU, Johnson D, Ginocchio M (2000) Burn injury in kitchen workers: a cause for prevention. J Burn Care Rehabil 21, 563-4, discussion 562. [Medline] [CrossRef]

21) McCaig LF, Burt CW, Stussman BJ (1998) A comparison of work-related injury visits and other injury visits to emergency departments in the United States, 1995-1996. J Occup Environ Med 40, 870-5. [Medline] [CrossRef]

22) Nakata A, Ikeda T, Takahashi M, Haratani T, Hojou M, Fujioka Y, Swanson NG, Araki S (2006) Impact of psychosocial job stress on non-fatal occupational injuries in small and medium-sized manufacturing enterprises. Am J Ind Med 49, 658-69. [Medline] [CrossRef]

23) Li CY, Chen KR, Wu CH, Sung FC (2001) Job stress and dissatisfaction in association with non-fatal injuries on the job in a cross-sectional sample of petrochemical workers. Occup Med (Lond) 51, 50-5. [Medline] [CrossRef]

24) Kim HC, Min JY, Min KB, Park SG (2009) Job strain and the risk for occupational injury in small- to medium-sized manufacturing enterprises: a prospective study of 1,209 Korean employees. Am J Ind Med 52, 322-30. [Medline] [CrossRef]

25) Haukka E, Leino-Arjas P, Ojajärvi A, Takala EP, ViikariJuntura E, Riihimäki H (2011) Mental stress and psychosocial factors at work in relation to multiple-site musculoskeletal pain: a longitudinal study of kitchen workers. Eur J Pain 15, 432-8. [Medline] [CrossRef]

26) Nagasu M, Sakai K, Ito A, Tomita S, Temmyo Y, Ueno M, Miyagi S (2007) Prevalence and risk factors for low back pain among professional cooks working in school lunch services. BMC Public Health 7, 171 [CrossRef]. [Medline]

27) Ono Y, Nakamura R, Shimaoka M, Hiruta S, Hattori Y, Ichihara G, Kamijima M, Takeuchi Y (1998) Epicondylitis among cooks in nursery schools. Occup Environ Med 55, 172-9. [Medline] [CrossRef]

28) Shimomitsu T. Manual of the Brief Job Stress Qustionnaire: Reports on the study of job stress and its effects on health in the workplace. 2005. http://www.tmu-ph.ac/topics/ stress_table.php. Accessed March 1, 2013.

29) Kato S, Doi Y, Tsutsui S, Makino M (2004) Job stress among Japan Overseas Cooperation volunteers - using the Brief Job Stress Questionnaire. Sangyo Eiseigaku Zasshi 
46, 191-200 (in Japanese). [Medline] [CrossRef]

30) Haruyama Y, Muto T, Matsuzuki H, Ito A, Tomita S, Muto S, Haratani T, Seo A, Ayabe M, Katamoto S (2010) Evaluation of subjective thermal strain in different kitchen working environments using subjective judgment scales. Ind Health 48, 135-44. [Medline] [CrossRef]

31) Gandi JC, Wai PS, Karick H, Dagona ZK (2011) The role of stress and level of burnout in job performance among nurses. Ment Health Fam Med 8, 181-94. [Medline]

32) Chen SW, Wang PC, Hsin PL, Oates A, Sun IW, Liu SI (2011) Job stress models, depressive disorders and work performance of engineers in microelectronics industry. Int Arch Occup Environ Health 84, 91-103. [Medline] [CrossRef]

33) Day AJ, Brasher K, Bridger RS (2012) Accident proneness revisited: the role of psychological stress and cognitive failure. Accid Anal Prev 49, 532-5. [Medline] [CrossRef]

34) Wadsworth EJ, Simpson SA, Moss SC, Smith AP (2003) The Bristol Stress and Health Study: accidents, minor injuries and cognitive failures at work. Occup Med (Lond) 53, 392-7. [Medline] [CrossRef] 